\title{
molecules
}

ISSN 1420-3049

www.mdpi.com/journal/molecules

Article

\section{Triacylglyceride, Antioxidant and Antimicrobial Features of Virgin Camellia oleifera, $C$. reticulata and $C$. sasanqua Oils}

\author{
Xesús Feás ${ }^{1}$, Leticia M. Estevinho ${ }^{2}$, Carmen Salinero ${ }^{3}$, Pilar Vela ${ }^{3}$, María J. Sainz ${ }^{4}$, \\ María Pilar Vázquez-Tato ${ }^{1}$ and Julio A. Seijas ${ }^{1, *}$
}

1 Department of Organic Chemistry, Faculty of Sciences, University of Santiago de Compostela, E-27080 Lugo, Spain; E-Mails: xesus.feas@usc.es (X.F.); pilar.vazquez.tato@usc.es (M.P.V.-T.)

2 CIMO-Mountain Research Center, Agricultural College of Bragança, Polytechnic Institute of Bragança, Campus Santa Apolónia, E 5301-855 Bragança, Portugal; E-Mail: leticia@ipb.pt

3 Areeiro Phytopathological Station, Pontevedra Deputation, Subida a la Robleda s/n, E36153 Pontevedra, Spain; E-Mails: carmen.salinero@depo.es (C.S.); pilar.vela@depo.es (P.V.)

Department of Plant Production, Faculty of Veterinary Sciences,

University of Santiago de Compostela, E-27002 Lugo, Spain; E-Mail: mj.sainz@usc.es

* Author to whom correspondence should be addressed; E-Mail: julioa.seijas@usc.es;

Tel.: +34-982-824-062; Fax: +34-982-824-001.

Received: 13 March 2013; in revised form: 9 April 2013 / Accepted: 15 April 2013 /

Published: 18 April 2013

\begin{abstract}
Virgin oils obtained from seeds of Camellia oleifera (CO), Camellia reticulata (CR) and Camellia sasanqua (CS) were studied for their triacylglyceride composition, antioxidant and antimicrobial activities. Levels of fatty acids determined by ${ }^{1} \mathrm{H}$-nuclear magnetic resonance analysis were similar to those reported for olive oils $(82.30 \%-84.47 \%$; $5.69 \%-7.78 \% ; 0.26 \%-0.41 \%$ and $8.04 \%-11.2 \%$, for oleic, linoleic, linolenic and saturated acids, respectively). The $\mathrm{CR}$ oil showed the best antioxidant potential in the three in vitro models tested. With regard to $\mathrm{EC}_{50}$ values $(\mu \mathrm{g} / \mathrm{mL})$, the order in DPPH radical-scavenging was CR (33.48) < CO (35.20) < CS (54.87). Effectiveness in reducing power was CR $(2.81)<\mathrm{CO}(3.09)<\mathrm{CS}$ (5.32). $\mathrm{IC}_{50}$ for LPO inhibition were $0.37,0.52$ and $0.75 \mu \mathrm{g} / \mathrm{mL}$ for $\mathrm{CR}, \mathrm{CO}$ and $\mathrm{CS}$, respectively. All the oils showed antimicrobial activity, and exhibited different selectivity and MICs for each microorganism tested (E. coli, B. cereus and C. albicans). B. cereus was the less sensitive species (MIC: $52.083 \pm 18.042$ for CO; $41.667 \pm 18.042$ for $\mathrm{CR} ; 104.167 \pm 36.084$ for $\mathrm{CS} \mathrm{mg} / \mathrm{mL}$ ) and the E. coli was the most sensitive to camellia oil's effect. The standard gentamicin presented higher MIC for E. coli (4.2) than the $\mathrm{CR}(\mathrm{MIC}=2.6)$ and $\mathrm{CO}(\mathrm{MIC}=3.9)$ oils.
\end{abstract}


Keywords: antioxidant potential; antimicrobial activity; Camellia; oil; triacylglyceride

\section{Introduction}

The genus Camellia (Theaceae) is native to East Asia and comprises more than 200 woody evergreen species [1]. Some species possess great economic value, particularly $C$. sinensis (the tea plant) which is grown commercially mainly in tropical and subtropical regions. Other species such as C. japonica, C. reticulata and C. sasanqua are cultivated in temperate regions worldwide as ornamentals. The seeds of Camellia species can be pressed to obtain high quality oils, some of which have been used for years in Asian cultures. The oil from C. oleifera (widely known as tea seed oil or tea oil) is used extensively in the Hunan Province in China for cooking, and C. japonica oil has a long history of traditional cosmetic usage in Japan as a protectant to maintain the health of skin and hair [2].

Camellia spp. have been used also in Oriental ethnomedicine and appear to be very promising leads for possible pharmaceutical exploitation since modern science has made it possible to specify their potential medical significance with antimicrobial [3], antioxidant [4,5], anti-allergic [6,7], antiviral [8,9] and skin healing properties [2]. However, there is relatively little information on the biological activity of the oils from Camellia species, except for tea oil [10-14]. The unsaturated fatty acid content in tea oil can reach as much as $90 \%$, which is the highest amount so far reported for unsaturated fatty acids in edible oils. Furthermore, tea oil is rich in catechin, polyphenols, saponin and squalene, which have good whitening and antioxidation, anti-permeability, anti-inflammatory, analgesic and anticancer properties [15]. Moreover, Camellia oil is often the target for adulteration or mislabeling because it is a high priced product with high nutritional and medical values [16].

Galicia (NW Spain) has a strong and increasing presence in Camellia markets. Today, the bulk of the industry's exports are as young plants for flowering and gardening purposes, but this is gradually increasing to provide a more diverse and value added portfolio, and in this context the production of Camellia oil appears as a new opportunity.

In the present work virgin Camellia oils produced in Galicia from seeds of C. oleifera, C. reticulata and $C$. sasanqua were studied for their: (a) triacylglyceride composition by ${ }^{1} \mathrm{H}$-nuclear magnetic resonance ( $\left.{ }^{1} \mathrm{H}-\mathrm{NMR}\right)$ analysis, (b) antioxidant potential [by (i) 2,2-diphenyl-1-picrylhydrazyl (DPPH) radical, (ii) reducing power and (iii) $\beta$-carotene bleaching assays] and (c) antimicrobial activity (against clinically isolated strains of Escherichia coli, Bacillus cereus and Candida albicans). The information obtained from the present study can be used to evaluate the potential use of Camellia oil as food product for improving human health and nutrition, as well as for other uses such as cooking/salad oil, food ingredient and in several industrial applications.

\section{Results and Discussion}

\subsection{Triacylglycerol Profile}

Edible oils are mainly made up of TAG which comprises more than $95 \%$ to $99 \%$ of the total lipids present. Each type of oil has a different TAG profile which determines the nature of its 
physicochemical and nutritional properties, and also provides information on the quality of the oil. In recent years, both industry and consumers have shown an increased interest in oils' compositions. However, simple identification and quantification of TAG is not sufficient, because of its dependence on many factors, such as number and position(s) of double bonds, type of fatty acid, chain lengths and their positions on the glycerol backbone [17].

Figure 1 shows the expanded ${ }^{1} \mathrm{H}-\mathrm{NMR}$ spectrum of the analyzed Camellia oils. Vinylic hydrogens have a characteristic chemical shift, and could be used to determine the ratio of saturated to unsaturated esters. Bisallylic $\mathrm{H}$ could be used to differentiate the nature of the unsaturated components. Finally, the tertiary $\mathrm{H}$ in the glycerin moiety could be used to quantify the ratio of saturated to unsaturated esters since there is only one $\mathrm{H}$ for each TAG molecule. ${ }^{1} \mathrm{H}-\mathrm{NMR}$ has become one of the most promising methods to determine organic structures in complex matrices since do not depend on the efficiency of the sample treatment processes [18]. In ${ }^{1} \mathrm{H}-\mathrm{NMR}$ methodology, data is collected without sample pretreatment, thus rendering a simpler and faster analysis than the conventional methods. Moreover, it avoids several problems, such as lipid oxidation, involved in the traditional GC analysis and it does not require calibration with standards [19]. Furthermore, ${ }^{1} \mathrm{H}-\mathrm{NMR}$ offers advantages over HPLC or GC methodology because it allows the simultaneous, noninvasive, and nondestructive study of oil composition, and also provides information about the acyl position and distribution of TAGs [20-24]. However a magnetic field equal to $7.05 \mathrm{~T}$ (300 MHz) does not provide enough resolution to avoid signal overlapping between linoleic and linolenic acids. Magnetic fields equal to or higher than $9.4 \mathrm{~T}(400 \mathrm{MHz})$ are more appropriate [25], since a typical spectra obtained with $300 \mathrm{MHz}$ spectrometer did not allow the accurate integration of the tertiary $\mathrm{H}$ of the glycerin moiety, and no difference was found between bisallylic $H(\delta=2.80$ ppm approx. $)$ [26]. The use of a $750 \mathrm{MHz}$ spectrometer to analyze the samples rendered a higher resolution spectra that in turn allowed for the separated integration of the signal from the tertiary glycerin $\mathrm{H}$, and the vinylic ones.

Levels in percentage of $\mathrm{C}_{18}$ unsaturated [oleic acid (OA, C18:1n9c+t), linoleic acid (LA, C18:2n6c) and linolenic acid (LNA, C18:3n3)], the total saturated FA (SFA), monounsaturated FA (MUFA), polyunsaturated FA (PUFA), total unsaturated FA (TUFA $=\sum$ MUFA $+\sum$ PUFA) and the ratios PUFA/SFA, SFA/TUFA, and $\omega-6 / \omega-3, \omega-3 / \omega-6$, obtained for the virgin CO, CR and CS oil samples are shown in Table 1 . The principal fatty acid found was oleic acid, ranging between $82.30 \%$ and $84.47 \%$. It was followed by linoleic $(5.69 \%$ to $7.78 \%)$ and linolenic $(0.30$ to 0.41$)$. SFA and MUFA are synthesized endogenously in humans; however, PUFA needs to be supplied exogenously. The LA and LNA are key compounds for cell membranes and are associated to brain function and neurotransmission. These FA also play an important role in the transference of the $\mathrm{O}_{2}$ to blood plasma, in the synthesis of hemoglobin and in cellular division [27-29]. Moreover, FA from $\omega-6$ series are biogenetic precursors of some physiologically important thromboxanes, leukotrienes and prostaglandins hormones, which are related to the inflammatory response. The nutritional value of essential $\omega-3$ and $\omega-6$ FA is also widely known for its health beneficial effects [30].

All the analyzed samples showed PUFA/SFA ratios above 0.58 and n- $6 / n-3$ fatty acids of 0.05 (Table 1). PUFA/SFA ratios are used to calculate the risk factor of foods, since it is known that SFA increases the plasma cholesterol levels, while PUFA decreases them. 
Figure 1. ${ }^{1} \mathrm{H}-\mathrm{NMR}$ spectra $\left(750 \mathrm{MHz}\right.$ for $\left.{ }^{1} \mathrm{H}\right)$ of C. oleifera $(\mathbf{A})$, C. reticulata $(\mathbf{B})$ and C. sasanqua (C) oils.

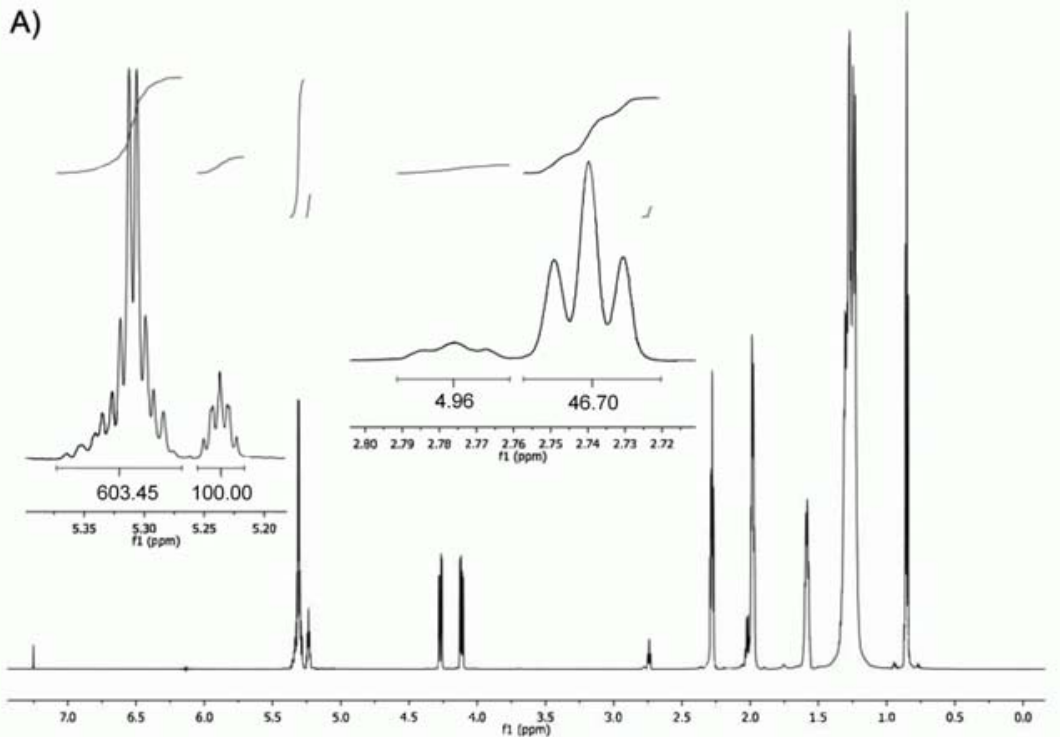

B)

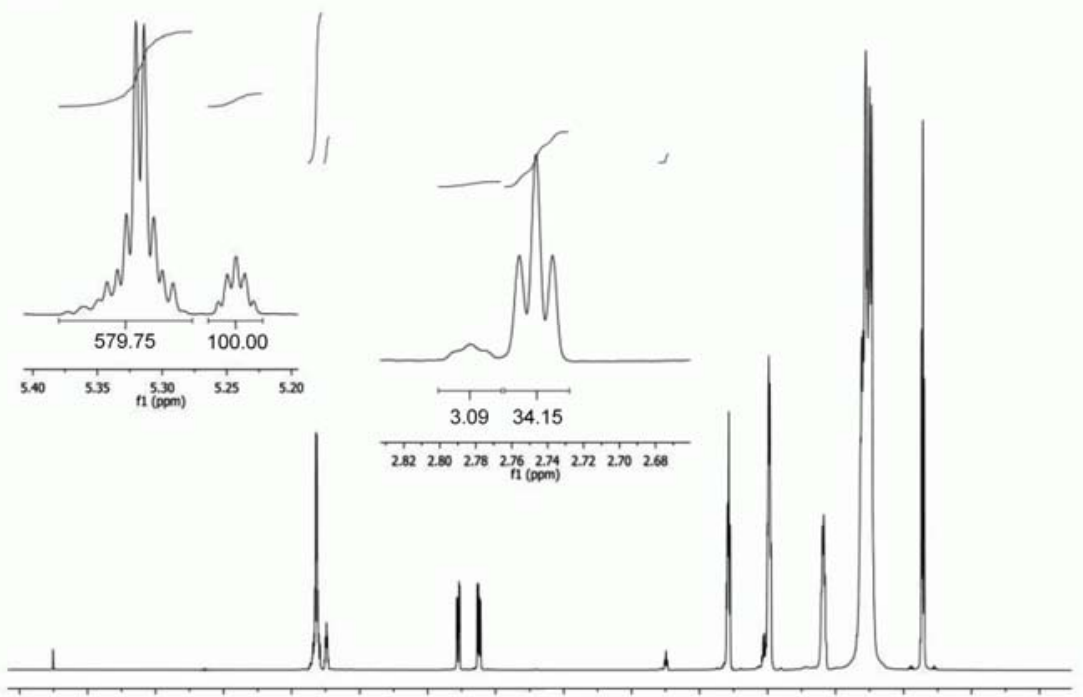

C)

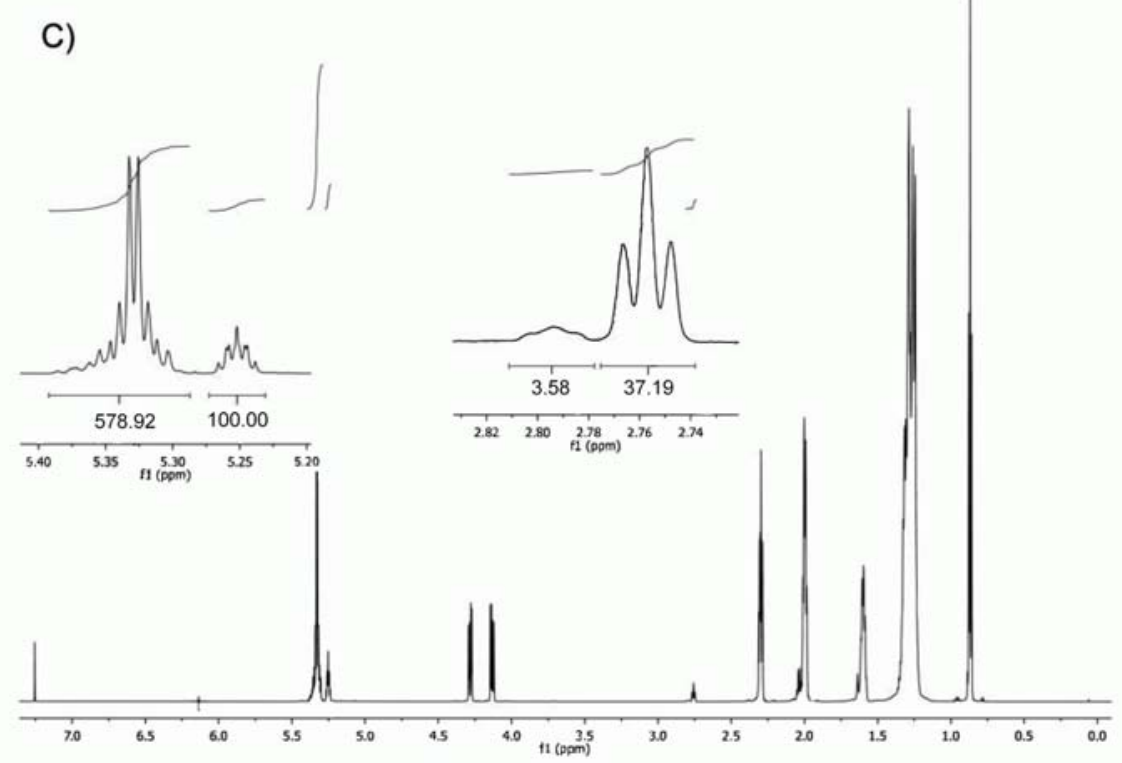


Table 1. Levels (\%) of fatty acid composition obtained for Camellia oils investigated.

\begin{tabular}{|c|c|c|c|c|c|c|c|c|c|c|c|c|c|}
\hline Oil & $C 18: \ln 9 c+t$ & C18:2n6c & C18:3n3 & $\sum$ SFA & $\sum$ MUFA & $\sum$ PUFA & $\sum$ TUFA & $\omega 6 / \omega 3$ & $\omega 3 / \omega 6$ & PUFA/SFA & TUFA/SFA & SFA/TUFA & Reference \\
\hline Virgin $C$. oleifera & 83.77 & 7.78 & 0.41 & 8.04 & 83.77 & 8.19 & 91.96 & 0.05 & 18.98 & 1.02 & 11.44 & 0.09 & $\mathrm{PW} *$ \\
\hline Virgin $C$. reticulata & 84.47 & 5.69 & 0.26 & 9.58 & 84.47 & 5.95 & 90.42 & 0.05 & 21.88 & 0.62 & 9.44 & 0.11 & $\mathrm{PW} *$ \\
\hline Virgin C. sasanqua & 82.3 & 6.2 & 0.3 & 11.2 & 82.30 & 6.5 & 88.80 & 0.05 & 20.67 & 0.58 & 7.93 & 0.13 & $\mathrm{PW} *$ \\
\hline C. japonica & 80.67 & 6.65 & 0.29 & 10.0 & 80.67 & 6.94 & 87.61 & 0.04 & 22.93 & 0.69 & 8.76 & 0.11 & {$[21]$} \\
\hline Virgin olive & 80 & 5.9 & 0.7 & 13.4 & 80.00 & 6.60 & 86.60 & 0.12 & 8.43 & 0.49 & 6.46 & 0.15 & {$[22]$} \\
\hline Olive & 77.5 & 7.4 & 0.7 & 14.4 & 77.50 & 8.10 & 85.60 & 0.09 & 10.57 & 0.56 & 5.94 & 0.17 & [22] \\
\hline Hazelnut & 81 & 10.7 & nd & 8.3 & 81.00 & 10.70 & 91.70 & 0.00 & - & 1.29 & 11.05 & 0.09 & [22] \\
\hline Corn & 33 & 51 & 0.7 & 15.3 & 33.00 & 51.70 & 84.70 & 0.01 & 72.86 & 3.38 & 5.54 & 0.18 & [22] \\
\hline Sunflower & 29.2 & 58.8 & nd & 12 & 29.20 & 58.80 & 88.00 & 0.00 & - & 4.90 & 7.33 & 0.14 & [22] \\
\hline Linseed & 20 & 17.1 & 54.2 & 8.7 & 20.00 & 71.30 & 91.30 & 3.17 & 0.32 & 8.20 & 10.49 & 0.10 & [22] \\
\hline Avocado & 65 & 10 & 1 & 20 & 65.00 & 11.00 & 76.00 & 0.10 & 10.00 & 0.55 & 3.80 & 0.26 & [23] \\
\hline Tea seed & 80 & 10 & $<1$ & 10 & 80.00 & - & - & - & - & - & - & - & [23] \\
\hline Pumpkin & 40.0 & 40.0 & $<1$ & 10.0 & 40.00 & - & - & - & - & - & - & - & {$[23]$} \\
\hline Soybean & 25.0 & 50.0 & 7.0 & 15.0 & 25.00 & 57.00 & 82.00 & 0.14 & 7.14 & 3.80 & 5.47 & 0.18 & [23] \\
\hline Canola & 60.0 & 20.0 & 10.0 & 7.0 & 60.00 & 30.00 & 90.00 & 0.50 & 2.00 & 4.29 & 12.86 & 0.08 & [23] \\
\hline
\end{tabular}

* Present work. Capric acid (C10:0); Palmitic acid (C16:0); Oleic acid (C18:1n9c+t); Linoleic acid (C18:2n6c); $\alpha$-Linolenic acid (C18:3n3); Arachidic acid (C20:0); Eicosenoic acid $(\mathrm{C} 20: 1 \mathrm{c})$. SFA: Saturated fatty acids $(\mathrm{C} 10: 0+\mathrm{C} 16: 0+\mathrm{C} 20: 0)$; MUFA: Monounsaturated fatty acids $(\mathrm{C} 18: 1 \mathrm{n} 9 \mathrm{c}+\mathrm{t}+\mathrm{C} 20: 1 \mathrm{c})$; PUFA: Polyunsaturated fatty acids $(\mathrm{C} 18: 2 n 6+\mathrm{C} 18: 3 n 3)$;

TUFA: Total unsaturated fatty acids ( $\sum$ MUFA $+\sum$ PUFA). 
For comparative purposes, typical levels (in \%) of $\mathrm{C}_{18}$ unsaturated FA, total saturated FA and ratios in common oils are shown in Table 1. Camellia oil has fatty acid composition similar to olive oil, in fact, it sometimes is referred to as the "olive oil of Asia" [10].

\subsection{Antioxidant Activity}

Results obtained for antioxidant activity of investigated Camellia oil samples are reported in the Table 2. In our research we used three established in vitro systems, since the antioxidant properties of food matrices cannot be evaluated by just one method due to the complex nature of their constituents.

Table 2. Values $(\mathrm{mg} / \mathrm{mL})$ obtained in the antioxidant activity assays $\left(\mathrm{EC}_{50}\right.$ for $\mathrm{DPPH}$ radical-scavenging activity and reducing power, and $\mathrm{IC}_{50}$ for inhibition of lipid peroxidation) of Camellia oils tested.

\begin{tabular}{ccccc}
\hline Test & C. oleifera & C. reticulata & C. sasanqua & Control \\
\hline DPPH scavenging & $35.20 \pm 4.95 \mathrm{ab}$ & $33.48 \pm 7.65 \mathrm{a}$ & $54.87 \pm 8.78 \mathrm{c}$ & $47.02 \pm 2.98 \mathrm{bc}$ \\
Reducing power & $3.09 \pm 0.92 \mathrm{a}$ & $2.81 \pm 0.63 \mathrm{a}$ & $5.32 \pm 0.98 \mathrm{~b}$ & $30.11 \pm 1.67 \mathrm{c}$ \\
LPO inhibition & $0.52 \pm 0.01 \mathrm{a}$ & $0.37 \pm 0.01 \mathrm{a}$ & $0.75 \pm 0.02 \mathrm{~b}$ & $3.24 \pm 0.56 \mathrm{c}$ \\
\hline
\end{tabular}

In each column different letters mean significant differences $(p<0.05)$; Values for the standard Trolox in $\mu \mathrm{g} / \mathrm{mL}$.

The results obtained for the tested oils in each method used are shown below, with percent values in parenthesis. The results for $\mathrm{CR}$ and $\mathrm{CO}$ are similar, but superior in comparison with CS:

- $\quad$ DPPH scavenging activity $\left(\mathrm{EC}_{50}\right): \mathrm{CR}(33.48)<\mathrm{CO}(35.20)<\mathrm{CS}(54.87)$

- Reducing power $\left(\mathrm{EC}_{50}\right)$ : $\mathrm{CR}(2.81)<\mathrm{CO}(3.09)<\mathrm{CS}(5.32)$

- $\quad$ LPO inhibition $\left(\mathrm{IC}_{50}\right)$ : CR $(0.37)<\mathrm{CO}(0.52)<\mathrm{CS}(0.75)$

Significant differences were found between the values obtained for the antioxidant activity of the different oils, using the three methodologies. The mean obtained for the oil of $C$. sasanqua was, in all cases, significantly different from the results obtained for $C$. oleifera and $C$. reticulata. The antioxidant potential of the control always differed significantly from the potential of the samples.

In the present work cold-pressed oil was employed since refined vegetable oils present reduced amounts of antioxidants as a consequence of the refining process [31]. Peroxidation of lipids is a process with important implications: it shortens the shelf-life of food and drugs, causes fragmentation of DNA, damages cellular membranes and promotes the genesis of many human diseases. Much effort is therefore devoted to search for "potent antioxidants", both synthetic and from natural sources, particularly from plants [32]. Moreover, the crucial role of lipids in cell, tissue and organ physiology is demonstrated by genetic studies and human diseases that involve the disruption of lipid metabolic enzymes and pathways [18].

Extensive studies have been made about the total antioxidant capacity of edible vegetable oils, to prevent the presumed deleterious effects of free radicals in the human body, and to prevent the deterioration of fats and other constituents of foodstuffs. Nevertheless, to our knowledge there is scarce data reporting the antioxidant potential of Camellia oil and available works are focused on extracts, which involve the use of several organic solvents and not on whole oil material $[11,13]$. Based on the scavenging effects of different extracts of tea seed oil on DDPH radical it was suggested 
that apart from its traditional pharmacological effects, the tea seed oil may also act as a prophylactic agent to prevent free radical related diseases [33]. Zhang showed that the refined CO is capable to scavenge $\cdot \mathrm{OH}$ free radicals with an $\mathrm{EC}_{50}$ of $0.7165 \mu \mathrm{g} / \mathrm{mL}$, equivalent to that of $5.31 \mu \mathrm{g} / \mathrm{mL}$ quercetin [27]. The methanol extract of $\mathrm{CO}$ exhibited pronounced radical scavenging activity against the stable DPPH radical (with antioxidant capacity $\mathrm{EC}_{50}$ value of $52.37 \mu \mathrm{g} / \mathrm{mL}$ ). In fact, sesamin and 2,5-bisbenzo[1,3]dioxol-5-yl-tetrahydrofuro[3,4-d][1,3]dioxin were isolated from the methanol extract of CO and both compounds have remarkably protective effects against oxidative stress-related damages [33].

\subsection{Antimicrobial Activity}

Table 3 shows the antimicrobial activity screening of the three Camellia oils $(C$. reticulata, C. oleifera and C. sasanqua) on the bacterial strains (B. cereus - Gram positive and E. coli - Gram negative) and yeast ( $C$. albicans). The MIC was used as a parameter of the significant inhibitory effects induced by oils on the growth of the tested microorganisms, as indicated by the TCC staining (dead cells are not stained by TTC). All the oils evidenced antimicrobial activity, and showed different selectivity and MICs for each microorganism. CR oil showed best antimicrobial activity in comparison with the other oils used for all microorganisms tested, followed by $\mathrm{CO}$ and CS.

Table 3. Minimum inhibitory concentration (MIC, in $\mathrm{mg} / \mathrm{mL}$ ) for the studied microorganisms in the antimicrobial activity assays with Camellia oils.

\begin{tabular}{ccccc}
\hline MIC & C. oleifera & C. reticulata & C. sasanqua & Control \\
\hline B. cereus $($ ESA 239) & $52.083 \pm 18.042 \mathrm{~b}$ & $41.667 \pm 18.042 \mathrm{~b}$ & $104.167 \pm 36.084 \mathrm{c}$ & $5.08 \pm 0.35 \mathrm{a}^{1}$ \\
C. albicans (ESA 567) & $20.833 \pm 7.217 \mathrm{ab}$ & $20.833 \pm 7.217 \mathrm{ab}$ & $29.167 \pm 19.094 \mathrm{~b}$ & $0.65 \pm 0.56 \mathrm{a}^{2}$ \\
E. coli $($ ESA 34) & $3.917 \pm 3.406 \mathrm{ab}$ & $2.600 \pm 1.125 \mathrm{ab}$ & $5.883 \pm 3.406 \mathrm{~b}$ & $4.22 \pm 1.32 \mathrm{a} \mathrm{a}^{1}$ \\
\hline In each column different letters mean significant differences $(p<0.05) .{ }^{1}{ }^{1}$ Gentamicin and ${ }^{2}$ amphotericin B in $\mu \mathrm{g} / \mathrm{mL}$.
\end{tabular}

The treatment of bacterial infections is increasingly complicated by the ability of the bacteria to develop resistance to antimicrobial agents [34]. Numerous reports have emphasized the need for less and better use of antibacterials, improved infection control, and the development of new agents [35]. Some of the common nosocomial infections, caused by B. cereus, E. coli and C. albicans, are urinary tract infections, respiratory pneumonia, surgical site wound infections, bacteremia, gastrointestinal and skin infections.

B. cereus was the less sensitive species to the Camellia oils' effect (MIC: $52.083 \pm 18.042 \mathrm{mg} / \mathrm{mL}$ for $\mathrm{CO} ; 41.667 \pm 18.042 \mathrm{mg} / \mathrm{mL}$ for $\mathrm{CR} ; 104.167 \pm 36.084 \mathrm{mg} / \mathrm{mL}$ for CS). B. cereus is a widely distributed foodborne pathogen that causes vomiting and diarrhea in mammals, including humans. Interest in $B$. cereus has been growing lately because it seems that $B$. cereus-related diseases, in particular food poisonings, are growing in number [36]. Although B. cereus is associated mainly with food poisoning, it has been increasingly reported to be a cause of serious and potentially fatal non-gastrointestinal-tract infections [37].

Antimicrobial activity of the tested Camellia oils against C. albicans was more homogenous, the obtained MICs ranging between $20.833 \pm 7.217 \mathrm{mg} / \mathrm{mL}$ (for CO and CR) to $29.167 \pm 19.094 \mathrm{mg} / \mathrm{mL}$ for CS. The incidence of fungal infections is increasing in community and hospital environments [38], and no other mycotic pathogen produces such a spectrum of opportunistic diseases in humans and 
animals as Candida does [39]. As it is very difficult to eliminate these microorganisms, due to their resistance to most antimicrobial agents, we decided to test the effect of camellia oil against them.

E. coli was the most sensitive to the Camellia oil's effect, showing the control used (gentamicin) higher MIC (4.2) than the $\mathrm{CR}(\mathrm{MIC}=2.6)$ and $\mathrm{CO}(\mathrm{MIC}=3.9)$ oils. E. coli is a highly adapted pathogen capable of causing a range of diseases, from gastroenteritis to extraintestinal infections of the urinary tract, bloodstream and central nervous system [40]. The worldwide burden of these diseases is staggering, with hundreds of millions of people affected annually [41]. Moreover, E. coli has shown some resistance to gentamicin [42]. Recently, it was found that oil tea saponin extracted from the residual oil tea seed cakes had a remarkably restraining effect on the bacteria E. coli, Staphylococcus aureus, and Bacillus subtilis and on the fungi Mucor racemosus, Aspergillus oryzae, Rhizophus stolonifer, Saccharomyces cerevisiae and Penicillium glaucum [43,44].

Significant differences were found between the antimicrobial activity of the control and the obtained for the oils. Similarly to the observed concerning the antioxidant activity, the antimicrobial activity of the $C$. sasanqua oil was, in all cases, significantly different from the obtained for $C$. oleifera and $C$. reticulata.

Generally it is shown that Gram (-) bacteria are more resistant to plant based antimicrobials than Gram (+) bacteria. This may be explained by the structural differences of the bacterial cell wall. Gram (-) bacteria, apart from the cell membrane, possess an additional outer layer membrane, which consists of phospholipids, proteins and lipopolysaccharides, and this membrane is impermeable to most molecules. However, our results indicate that the tested Camellia oils can outcome in greater growth inhibition of Gram (-) bacteria than Gram (+). These findings agree with results from other studies about antimicrobial activity of saponin-rich fraction from Camellia oleifera cake [45] and the proanthocyanidin fraction separated from the crude Camellia tea extract [46]. However, the mechanisms of action of the antibacterial activity of saponins against both Gram $(-)$ and Gram $(+)$ bacteria are not yet clear $[42,47]$.

\section{Experimental}

\subsection{Chemicals and Reagents}

2,2-Diphenyl-1-picryl-hydrazyl (DPPH) was obtained from Alfa Aesar (Ward Hill, MA, USA). 2,3,5-triphenyl-2H-tetrazolium chloride (TTC), linoleic acid (LA), polyoxyethylene (20) sorbitan monooleate (Tween 80), $\beta$-carotene, dimethyl sulfoxide (DMSO), ethyl acetate (EtOAc), trichloroacetic acid (TCA), 6-hydroxy-2,5,7,8-tetramethylchroman-2-carboxylic acid (Trolox ${ }^{\circledR}$ ), iron(III) chloride $\left(\mathrm{FeCl}_{3}\right)$, sodium dihydrogen phosphate $\left(\mathrm{NaH}_{2} \mathrm{PO}_{4}\right)$, disodium hydrogen phosphate $\left(\mathrm{Na}_{2} \mathrm{HPO}_{4}\right)$, potassium ferricyanide (III) $\left[\mathrm{K}_{3} \mathrm{Fe}(\mathrm{CN})_{6}\right]$ and deuterated chloroform $\left(\mathrm{CDCl}_{3}\right)$ were obtained from Sigma Chemical Co. (St. Louis, MO, USA). Trichloromethane (TCM), gentamicin and amphotericin B were obtained from Merck (Darmstadt, Germany). Methanol (MeOH) was obtained from Pronolab (Lisboa, Portugal). High purity and double distilled water (18 MX cm), which was used in all experiments, was obtained from a Milli-Q purification system (Millipore, Bedford, MA, USA). 


\subsection{Apparatus}

Spectrophotometric measurements were made using a Unicam Helios AlphaUV-visible spectrometer (Thermo Spectronic, Cambridge, UK). ${ }^{1} \mathrm{H}-\mathrm{NMR}$ analyses were performed on a Varian Inova $750\left(750 \mathrm{MHz}\right.$ for $\left.{ }^{1} \mathrm{H}\right)$ instrument (Agilent Technologies ${ }^{\circledR}$, Palo Alto, CA, USA), equipped with a $5 \mathrm{~mm}$ probe. Evaporation of organic solvents was performed with a rotavapor system, consisting of a rotary vacuum evaporator (Heidolph VV. 2000, Leuven, Belgium) with a water bath and a B169 vacuum pump (Buchi, Flawil, Switzerland). An Eppendorf ${ }^{\circledR}$ (Hamburg, Germany) model 5810 R centrifuge was used.

\subsection{Plant Material and Oil Extraction}

Samples of fruits of three Camellia species: C. oleifera (CO), C. reticulata (CR) and C. sasanqua (CS) were collected in autumn 2011 from one healthy plant of each Camellia species grown in the live germplasm Camellia bank at the Estación Fitopatolóxica do Areeiro (Pontevedra, Galicia, NW Spain). The harvest was carried out when fruits began to split open and the seeds were visible, a phenological stage of fruit development that corresponds to the $\mathrm{BBCH}$ stage 88 described for Camellia japonica [48]. For each plant, a seed sample of $1 \mathrm{~kg}$ was taken and divided into five $200 \mathrm{~g}$ subsamples. Oil extraction was performed for each subsample. After cold-pressing, the yield of Camellia oil obtained for each species was: $24.8 \%$ for $\mathrm{CO}, 19.1 \%$ for $\mathrm{CR}$, and $17.6 \%$ for $\mathrm{CS}$.

\section{4. ${ }^{1} H-N M R$ Analysis}

For triacylglycerols (TAG) analysis, each oil sample, weighing $0.2 \mathrm{~g}$, was dissolved in $400 \mu \mathrm{L}$ of $\mathrm{CDCl}_{3}$ shaken in a vortex mixer, and the resulting mixture was placed into a 5 -mm diameter ultra-precision nuclear magnetic resonance (NMR) sample tube. The temperature of the sample in the probe was $30^{\circ} \mathrm{C}$. The chemical shifts are reported in ppm, using the solvent proton signal as standard. The proton resonances of the TAG acyl chains were assigned as previously described [26] and are shown in Table 4. In order to increase the accuracy of the signal areas in representing the $\mathrm{H}$ amounts, the longitudinal relaxation time $\left(T_{1}\right)$ was determined by executing the pulse sequence inversion recovery [25]. The area of the signals was determined by using the software equipment, and the integrations were carried out three times to obtain average values. All figures of the ${ }^{1} \mathrm{H}-\mathrm{NMR}$ spectra and of the expanded ${ }^{1} \mathrm{H}-\mathrm{NMR}$ spectrum regions were plotted at a fixed value of absolute intensity to be valid for comparative purposes.

\subsection{Antioxidant Activity}

The oils were evaluated for antioxidant potential, after diluting aliquots in EtOAc [47], through in vitro model systems such as 1,1-diphenyl-2-picrylhydrazyl (DPPH) [49], $\beta$-carotene-linoleate model system (antioxidant activity-AA) and iron reducing capacity (reducing power) [50]. Trolox ${ }^{\circledR}$ was used as standard, its concentration ranged from 2.5 to $50 \mu \mathrm{g} / \mathrm{mL}$, depending on the methodology used. The $\mathrm{EC}_{50}$ value represents the concentration of the Camellia oil causing 50\% inhibition in each assay carried out. 
Table 4. Assignment of the signals of Camellia oils ${ }^{1} \mathrm{H}-\mathrm{NMR}$ spectra $\left(750 \mathrm{MHz}\right.$ for $\left.{ }^{1} \mathrm{H}\right)$.

\begin{tabular}{cccc}
\hline Signal & Functional group & Multiplicity & Chemical shift (ppm) \\
\hline $\mathbf{1}$ & $\mathrm{I}(\mathrm{t})-\mathrm{CH}_{3}$ & $\mathrm{t}$ & $0.89-0.86$ \\
$\mathbf{2}$ & $\mathrm{H}(\mathrm{m})-\mathrm{CH}_{2}-$ & $\mathrm{m}$ & $1.35-1.23$ \\
$\mathbf{3}$ & $\mathrm{G}(\mathrm{m})-\mathrm{CH}_{2}-\mathrm{C}-\mathrm{CO}_{2}-$ & $\mathrm{m}$ & $1.64-1.57$ \\
$\mathbf{4}$ & $\mathrm{D}(\mathrm{m})-\mathrm{CH}_{2}-\mathrm{CO}_{2}-$ & $\mathrm{m}$ & $2.02-1.98$ \\
$\mathbf{5}$ & $\mathrm{E}(\mathrm{m})-\mathrm{CH}_{2}-\mathrm{CO}_{2}-$ & $\mathrm{m}$ & $2.06-2.02$ \\
$\mathbf{6}$ & $\mathrm{F}(\mathrm{dt})-\mathrm{C}-\mathrm{CH}_{2}-\mathrm{C}=\mathrm{C}-$ & $\mathrm{dt}$ & $2.33-2.28$ \\
$\mathbf{7}$ & $\mathrm{C}(\mathrm{t})-\mathrm{C}=\mathrm{C}-\mathrm{CH}_{2}-\mathrm{C}=\mathrm{C}-$ & $\mathrm{t}$ & $2.78-2.74$ \\
$\mathbf{8}$ & $\mathrm{L}(\mathrm{m})-\mathrm{C}=\mathrm{C}-\mathrm{CH}_{2}-\mathrm{C}=\mathrm{C}-\mathrm{CH}{ }_{2}-\mathrm{C}=\mathrm{C}$ & $\mathrm{m}$ & $2.81-2.78$ \\
$\mathbf{9}$ & $\mathrm{A}(\mathrm{dd})-\mathrm{C}-\mathrm{CH}_{2}-\mathrm{O}-\mathrm{CO}-\mathrm{C}$ & $\mathrm{dd}$ & $4.15-4.06$ \\
$\mathbf{1 0}$ & $\mathrm{B}(\mathrm{dd})-\mathrm{C}-\mathrm{CH} \mathrm{C}_{2}-\mathrm{O}-\mathrm{CO}-\mathrm{C}$ & $\mathrm{dd}$ & $4.30-4.26$ \\
$\mathbf{1 1}$ & $\mathrm{K}(\mathrm{m}) \mathrm{CH}(-\mathrm{C}-\mathrm{O}-\mathrm{CO}-\mathrm{C}-)_{2}$ & $\mathrm{~m}$ & $5.27-5.24$ \\
$\mathbf{1 2}$ & $\mathrm{J}(\mathrm{m}) \mathrm{C}-\mathrm{HC}=\mathrm{CH}-\mathrm{C}$ & $\mathrm{m}$ & $5.37-5.30$ \\
\hline
\end{tabular}

Signal multiplicity: s, singlet; $d$, doublet; $t$, triplet; $m$, multiplet; $d$, doublet of triplets; $d d$, doublet of doublets. The signal number agrees with those in Figure 1.

\subsubsection{DPPH Scavenging Activity}

Various concentrations of oil $(300 \mu \mathrm{L})$ were mixed with $\mathrm{MeOH}$ solution $(2.7 \mathrm{~mL})$ containing $\mathrm{DPPH} \bullet\left(6 \times 10^{-5} \mathrm{~mol} / \mathrm{L}\right)$. The mixtures were shaken vigorously and left to stand for $60 \mathrm{~min}$ in the dark (until stable absorption values were obtained). The reduction of the DPPH• was measured by continuous monitoring and observing the decrease of absorption at $517 \mathrm{~nm}$. The radical-scavenging activity (RSA) was calculated as a percentage of DPPH discoloration using the equation: $\%$ RSA $=\left[\left(\mathrm{A}_{\mathrm{DPPH}}-\mathrm{A}_{\mathrm{S}}\right) / \mathrm{A}_{\mathrm{DPPH}}\right] \times 100$; where $\mathrm{A}_{\mathrm{S}}$ is the absorbance of the solution when the oil has been added at a particular level and $\mathrm{A}_{\mathrm{DPPH}}$ is the absorbance of the DPPH solution.

\subsubsection{Reducing Power Assay}

The oil $(2.5 \mathrm{~mL})$ was mixed with $0.2 \mathrm{M} \mathrm{Na} \mathrm{HPO}_{4}-\mathrm{NaH}_{2} \mathrm{PO}_{4}$ buffer $(2.5 \mathrm{~mL}$, $\mathrm{pH}$ 6.6) and $10 \mathrm{mg} / \mathrm{mL} \mathrm{K}_{3} \mathrm{Fe}(\mathrm{CN})_{6}(2.5 \mathrm{~mL})$. The mixture was incubated at $50{ }^{\circ} \mathrm{C}$ for $20 \mathrm{~min}$. After $100 \mathrm{mg} / \mathrm{mL}$ TCA $(2.5 \mathrm{~mL})$ was added, the mixture was centrifuged at $650 \mathrm{~g}$ for $10 \mathrm{~min}$. The upper layer $(2.5 \mathrm{~mL})$ was mixed with $\mathrm{H}_{2} \mathrm{O}(2.5 \mathrm{~mL})$ and $1.0 \mathrm{mg} / \mathrm{mL} \mathrm{FeCl}_{3}(0.5 \mathrm{~mL})$. The mixture absorbance was measured at $700 \mathrm{~nm}$. Oil concentration providing 0.5 of absorbance $\left(\mathrm{EC}_{50}\right)$ was calculated from the graph of absorbance against oil concentration in the solution.

\subsection{3. $\beta$-Carotene Bleaching (BCB) Assay}

A solution was prepared by dissolving $\beta$-carotene $(2 \mathrm{mg})$ in TCM $(10 \mathrm{~mL})$. Afterwards the aforesaid solution $(2 \mathrm{~mL}$ ) was pipetted into a $200 \mathrm{~mL}$ round-bottom flask, and then the organic solvent was removed at $40{ }^{\circ} \mathrm{C}$ under vacuum. LA (40 mg), Tween 80 emulsifier (400 mg) and distilled $\mathrm{H}_{2} \mathrm{O}$ $(100 \mathrm{~mL})$ were added to the flask. The mixture was shaken and a portion of this emulsion $(4.8 \mathrm{~mL})$ was transferred into different test tubes containing different oil concentrations $(200 \mu \mathrm{L})$. The tubes were shaken and incubated at $50{ }^{\circ} \mathrm{C}$ in a water bath. As soon as the emulsion was added to each tube, the zero time absorbance was measured at $470 \mathrm{~nm}$. Absorbance readings were then recorded at 20-min 
intervals until the control sample had changed colour. A blank, devoid of $\beta$-carotene, was prepared for background subtraction. Lipid peroxidation inhibition (LPO) was calculated using the following equation: $\mathrm{LPO}=(\beta$-carotene content after $2 \mathrm{~h}$ of assay/initial $\beta$-carotene content $) \times 100$.

\subsection{Antimicrobial Activity Tests}

\subsubsection{Microbial Strains}

The microorganisms used in this study were clinical strains of Bacillus cereus (ESA 239, from feces), Candida albicans (ESA 567, from mouth) and Escherichia coli (ESA 34, from urine), isolated in the Northeastern Hospital Center of Bragança (Portugal), and identified, using molecular biology techniques, in the Microbiology Laboratory of the Escola Superior Agraria (ESA) of Bragança.

\subsubsection{Growth Conditions}

Strains were stored in Muller-Hinton medium plus $20 \%$ glycerol at $-70{ }^{\circ} \mathrm{C}$. Before experimental use, cultures from solid medium were subcultivated in liquid media, Nutrient Broth for bacteria and Yeast Peptone Agar for yeasts, incubated overnight and used as the source of inoculums for each experiment. The inoculum for the assays were prepared by diluting cell mass in $0.85 \% \mathrm{NaCl}$ solution, adjusted to 0.5 MacFarland scale, confirmed by spectrophotometrical reading at $580 \mathrm{~nm}$ for B. cereus and $E$. coli, and $640 \mathrm{~nm}$ for C. albicans. Cell suspensions were finally diluted to $10^{4} \mathrm{CFU} / \mathrm{mL}$ in order to use them in the activity assays.

\subsubsection{Antimicrobial Assay}

Antimicrobial tests were carried out according to [51], using Nutrient Broth or Yeasts Peptone Dextrose on microplate (96 wells). Oil was diluted in DMSO and transferred into the first draw-well, and serial dilutions were performed. The inoculum was added to all wells and the plates were incubated at $37{ }^{\circ} \mathrm{C}$ for $24 \mathrm{~h} \mathrm{(B.} \mathrm{cereus} \mathrm{and} \mathrm{E.} \mathrm{coli)} \mathrm{and} 25^{\circ} \mathrm{C}$ for $48 \mathrm{~h}$ (C. albicans). Amphotericin B and gentamicin were used as controls. In each experiment a positive control (inoculated medium) and a negative control (medium) and DMSO control (DMSO with inoculated medium) was introduced. Antimicrobial activity was detected by adding $20 \mu \mathrm{L}$ of $0.5 \%$ TTC solution. The Minimum Inhibitory Concentration (MIC) was defined as the lowest concentration of Camellia oil that inhibited visible growth. Three independent repetitions of each oil sample were performed.

\subsection{Statistical Analysis}

All the experiments were performed in triplicate $(n=3)$ and the results were expressed as mean \pm standard deviation. The studies were conducted in a fully randomized manner and all the obtained data were tested regarding normal distribution (Shapiro-Wilk test) and homogeneity of variances (Levene and Brown-Forsythe tests). When these conditions were met, statistical analyses were performed using the One-dimensional Variance Analysis (One-way ANOVA) followed by a Tukey test. 


\section{Conclusions}

This study provides the first data on triacylglyceride, antioxidant and antibacterial activities of virgin Camellia oleifera, C. reticulata and C. sasanqua oils. $750 \mathrm{MHz}{ }^{1} \mathrm{H}-\mathrm{NMR}$ spectroscopy has proven to be a useful tool for the direct analysis of the triacylglyceride composition of these oils, their levels of FA being similar to those reported for olive oils. The data obtained clearly show the antioxidant and antimicrobial activities of the three oils, being E. coli the most sensitive to the Camellia oil's inhibitory growth effect. This finding opens new possibilities for future therapeutic applications of the analyzed Camellia oils, although further studies are needed to evaluate their potential in vivo use.

\section{Acknowledgments}

XUNTA DE GALICIA for financial support: Grants INCITE09 262346PR and PGIDIT06RAG26103PR. X.F. would also like to thank the Xunta de Galicia (Isidro Parga Pondal Program for young researchers, Grant No. IPP-020).

\section{References}

1. Ming, T.L.; Bartholomew, B. Theaceae. In Flora of China; Wu, Z.Y., Raven, P.H., Hong, D.Y., Eds.; Science Press: Beijing, China, and Missouri Botanical Garden: St. Louis, MO, USA, 2007; Volume 12, pp. 366-478.

2. Jung, E.; Lee, J.; Baek, J.; Jung, K.; Lee, J.; Huha, S.; Kim, S.; Koh, J.; Park, D. Effect of Camellia japonica oil on human type I procollagen production and skin barrier function. J. Ethnopharmacol. 2007, 112, 127-131.

3. Kim, K.Y.; Davidson, P.M.; Chung, H.J. Antibacterial activity in extracts of Camellia Japonica L. petals and its application to a model food system. J. Food Protect. 2001, 64, 1255-1260.

4. Onodera, K.; Hanashiro, K.; Yasumoto, T. Camellianoside, a novel antioxidant glycoside from the leaves of Camellia japonica. Biosci. Biotechnol. Biochem. 2006, 70, 1995-1998.

5. Chan, E.W.C.; Lim, Y.Y.; Chew, Y.L. Antioxidant activity of Camellia sinensis leaves and tea from a low land plantation in Malaysia. Food Chem. 2007, 102, 1214-1222.

6. Onodera, K.I.; Tsuha, K.; Yasumoto-Hirose, M.; Tsuha, K.; Hanashiro, K.; Naoki, H.; Yasumoto, T. Okicamelliaside, an extraordinarily potent anti-degranulation glucoside isolated from leaves of Camellia japonica. Biosci. Biotechnol. Biochem. 2010, 74, 2532-2534.

7. Kuba, M.; Tsuha, K.; Tsuha, K.; Matsuzaki, G.; Yasumoto, T. In vivo analysis of the anti-allergic activities of Camellia japonica extract and okicamelliaside, a degranulation inhibitor. J. Health Sci. 2008, 54, 584-588.

8. Park, J.C.; Hur, J.M.; Park, J.G.; Hatano, T.; Yoshida, T.; Miyashiro, H.; Min, B.S.; Hattori, M. Inhibitory effects of Korean medicinal plants and camelliatannin $\mathrm{H}$ from Camellia japonica on human immunodeficiency virus type 1 protease. Phytother. Res. 2002, 16, 422-426.

9. Akihisa, T.; Tokuda, H.; Ukiya, M.; Suzuki, T.; Enjo, F.; Koike, K.; Nikaido, T.; Nishino, H. 3-Epicabraleahydroxylactone and other triterpenoids from Camellia oil and their inhibitory effects on Epstein-Barr virus activation. Chem. Pharm. Bull. 2004, 52, 153-156. 
10. Ma, J.; Ye, H.; Rui, Y.; Chen, G.; Zhang, N. Fatty acid composition of Camellia oleifera oil. J. Verbr. Lebensm. 2011, 6, 9-12.

11. Zhang, L.L.; Wang, Y.M.; Wu, D.M.; Xu, M.; Chen, J.H. Comparisons of antioxidant activity and total phenolics of Camelia oleifera Abel fruit hull from different regions of China. J. Med. Plants Res. 2010, 4, 1420-1426.

12. Shen, J.; Zhang, Z.; Tian, B.; Hua, Y. Lipophilic phenols partially explain differences in the antioxidant activity of subfractions from methanol extract of Camellia oil. Eur. Food Res. Technol. 2012, 235, 1071-1082.

13. Lee, J.W.; Kim, Y.T.; Park, J.W.; Rheel, C. Antioxidation activity of oil extracts prepared from various seeds. Food Sci. Biotechnol. 2012, 21, 637-643.

14. Sokol'skii, I.N.; Ban'kovskii, A.I.; Zinkevich, É.P. Triterpene glycosides from Camellia oleifera and Camellia sasanqua. Chem. Nat. Compd. 1975, 11, 116-117.

15. Li, H.; Zhou, G.-Y.; Zhang, H.-Y.; Liu, J.-A. Research progress on the health function of tea oil. J. Med. Plants Res. 2011, 5, 485-489.

16. Wang, L.; Lee, F.S.C.; Wang, X.; He, Y. Feasibility study of quantifying and discriminating soybean oil adulteration in Camellia oils by attenuated total reflectance MIR and fiber optic diffuse reflectance NIR. Food Chem. 2006, 95, 529-536.

17. Zeb, A. Triacylglycerols composition, oxidation and oxidation compounds in camellia oil using liquid chromatography-mass spectrometry. Chem .Phys. Lipids 2012, 165, 608-614.

18. Wenk, M.R. The emerging field of lipidomics. Nat. Rev. Drug Discov. 2005, 4, 594-610.

19. Dais, P.; Spyros, A.; Christophoridou, S.; Hatzakis, E.; Fragaki, G.; Agiomyrgianaki, A.; Salivaras, E.; Siragakis, G.; Daskalaki, D.; Tasiolula-Margari, M.; Brenes, M. Comparison of Analytical Methodologies Based on ${ }^{1} \mathrm{H}$ and ${ }^{31} \mathrm{P}-\mathrm{NMR}$ Spectroscopy with Conventional Methods of Analysis for the Determination of Some Olive Oil Constituents. J. Agric. Food Chem. 2007, $55,577-584$.

20. Jie, M.S.; Mustafa, J. High-resolution nuclear magnetic resonance spectroscopy-Applications to fatty acids and triacylglycerols. Lipids 1997, 32, 1019-1034.

21. Guillén, M.D.; Ruiz, A. Study by means of ${ }^{1} \mathrm{H}$ nuclear magnetic resonance of the oxidation process undergone by edible oils of different natures submitted to microwave action. Food Chem. 2006, 96, 665-674.

22. Guillén, M.D.; Ruiz, A. High resolution ${ }^{1} \mathrm{H}$ nuclear magnetic resonance in the study of edible oils and fats. Trends Food Sci. Technol. 2001, 12, 328-338.

23. Haiyan, Z.; Bedgood, D.R.; Bishop, A.G.; Prenzler, P.D.; Robards, K. Endogenous biophenol, fatty acid and volatile profiles of selected oils. Food Chem. 2006, 100, 1544-1551.

24. Vlahov, G. Application of NMR to the study of olive oils. Prog. Nucl. Magn. Reson. Spectrosc. 1999, 35, 341-357.

25. Barison, A.; da Silva, C.W.; Campos, F.R.; Simonelli, F.; Lenz, C.A.; Ferreira, A.G. A simple methodology for the determination of fatty acid composition in edible oils through ${ }^{1} \mathrm{H}$ NMR spectroscopy. Magn. Res. Chem. 2010, 48, 642-650.

26. Salinero, C.; Feás, X.; Mansilla, J.P.; Seijas, J.A.; Vázquez-Tato, M.P.; Vela, P.; Sainz, M.J. ${ }^{1} \mathrm{H}$-nuclear magnetic resonance analysis of the triacylglyceride composition of cold-pressed oil from Camellia japonica. Molecules 2012, 17, 6716-6727. 
27. Escrich, E.; Moral, R.; Grau, L.; Costa, I.; Solanas, M. Molecular mechanisms of the effects of olive oil and other dietary lipids on cancer. Mol. Nutr. Food Res. 2007, 51, 1279-1292.

28. Kaya-Dagistanli, F.; Tanriverdi, G.; Altinok, A.; Ozyazgan, S.; Ozturk, M. The effects of alpha lipoic acid on liver cells damages and apoptosis induced by polyunsaturated fatty acids. Food Chem. Toxicol. 2013, 53, 84-93.

29. Pérez-Jiménez, F.; Ruano, J.; Pérez-Martinez, P.; López-Segura, F.; López-Miranda, J. The influence of olive oil on human health: Not a question of fat alone. Mol. Nutr. Food Res. 2007, 51, 1199-1208.

30. Castelo-Branco, V.N.; Torres, A.G. Generalized linear model describes determinants of total antioxidant capacity of refined vegetable oils. Eur. J. Lipid Sci. Tech. 2012, 114, 332-342.

31. Pinchuk, I.; Shoval, H.; Dotan, Y.; Lichtenberg, D. Evaluation of antioxidants: Scope, limitations and relevance of assays. Chem. Phys. Lipids 2012, 165, 638-647.

32. Lee, C.P.; Yen, G.C. Antioxidant activity and bioactive compounds of tea seed (Camellia oleifera Abel.) oil. J. Agric. Food Chem. 2006, 54, 779-784.

33. Zhang, Z.Y. Study on the Radiation Activity of Antioxidant Ingredients and Mechanism of Tea Oil; Zhejiang University Press: Hangzhou, China, 2006; pp. 1-36.

34. Tenover, F.C. Mechanisms of antimicrobial resistance in bacteria. Am. J. Med. 2006, 119, S3-S10.

35. Livermore, D.M. Bacterial resistance: Origins, epidemiology, and impact. Clin. Infect. Dis. 2003, $15,11-23$.

36. Kotiranta, A.; Lounatmaa, K.; Haapasalo, M. Epidemiology and pathogenesis of Bacillus cereus infections. Microbes Infect. 2000, 2, 189-198.

37. Bottone, E.J. Bacillus cereus, a volatile human pathogen. Clin. Microbiol. Rev. 2010, 23, 382-398.

38. Fridkin, S.K. The changing face of fungal infections in health care settings. Clin. Infect. Dis. 2005, 41, 1455-1460.

39. Tortorano, A.M.; Kibbler, C.; Peman, J.; Bernhardt, H.; Klingspor, L.; Grillot, R. Candidaemia in Europe: Epidemiology and resistance. Int. J. Antimicrob. Agents 2006, 27, 359-366.

40. Croxen, M.A.; Finlay, B.B. Molecular mechanisms of Escherichia coli pathogenicity. Nat. Rev. Microbiol. 2010, 8, 26-38.

41. Kaper, J.B.; Nataro, J.P.; Mobley, H.L. Pathogenic Escherichia coli. Nat. Rev. Microbiol. 2004, 2, 123-140.

42. Tadesse, D.A.; Zhao, S.; Tong, E.; Ayers, S.; Singh, A.; Bartholomew, M.J.; McDermott, P.F. Antimicrobial drug resistance in Escherichia coli from humans and food animals, United States, 1950-2002. Emerg. Infect. Dis. 2012, 18, 741-749.

43. Hu, J.L.; Nie, S.P.; Huang, D.F.; Li, C.; Xie, M.Y. Extraction of saponin from Camellia oleifera cake and evaluation of its antioxidant activity. Int. J. Food Sci. Tech. 2012, 47, 1676-1687.

44. Hu, J.L.; Nie, S.P.; Huang, D.F.; Li, C.; Xie, M.Y.; Wan, Y. Antimicrobial activity of saponinrich fraction from Camellia oleifera cake and its effect on cell viability of mouse macrophage RAW 264.7. J. Sci. Food Agric. 2012, 92, 2443-2449.

45. Amarowicz, R.; Pegg, R.B.; Bautista D.A. Antibacterial activity of green tea polyphenols against Escherichia coli K12. Nahrung 2000, 44, 60-62.

46. Hassan, S.M.; Haq, A.U.; Byrd, J.A.; Berhow, M.A.; Cartwright, A.L.; Bailey, C.A. Haemolytic and antimicrobial activities of saponin-rich extracts from guar meal. Food Chem. 2010, 119, 600-605. 
47. Pérez-Jiménez, J.; Arranz, S.; Tabernero, M.; Díaz-Rubio, M.E.; Serrano, J.; Goñi, I.; Saura-Calixto, F. Updated methodology to determine antioxidant capacity in plant foods, oils and beverages: Extraction, measurement and expression of results. Food Res. Int. 2008, 41, 274-285.

48. Vela, P.; Salinero, C.; Sainz, M.J. Phenological growth stages of Camellia japonica. Ann. Appl. Biol. 2013, 162, 182-190.

49. Ferreira, I.C.F.R.; Aires, E.; Barreira, J.C.M.; Estevinho, L.M. Antioxidant activity of Portuguese honey samples: Different contributions of the entire honey and phenolic extract. Food Chem. 2009, 114, 1438-1443.

50. Moreira, L.; Dias, L.G.; Pereira, J.A.; Estevinho, L. Antioxidant properties, total phenols and pollen analysis of propolis samples from Portugal. Food Chem. Toxicol. 2008, 46, 3482-3485.

51. Morais, M.; Moreira, L.; Feás, X.; Estevinho, L.M. Honeybee-collected pollen from five Portuguese Natural Parks: Palynological origin, phenolic content, antioxidant properties and antimicrobial activity. Food Chem. Toxicol. 2011, 49, 1096-1101.

Sample Availability: Samples of the oils are available from the authors.

(C) 2013 by the authors; licensee MDPI, Basel, Switzerland. This article is an open access article distributed under the terms and conditions of the Creative Commons Attribution license (http://creativecommons.org/licenses/by/3.0/). 